\title{
MiR-146a and miR-155 polymorphisms in Egyptian patients with Behcet's disease
}

Olfat G. Shaker ${ }^{1}$, Omayma O. Abdelaleem², Nermeen A. Fouad ${ }^{3}$, Naglaa A. Ahmed ${ }^{4}$, Hoda A. Hussein ${ }^{5}$, Enas G. Ibrahem ${ }^{6}$, Abdelrahmaan A. Mohamed ${ }^{6}$, Othman M. Ahmed ${ }^{7}$, Doaa Y. Ali

\author{
${ }^{1}$ Department of Medical Biochemistry and Molecular Biology, Faculty of Medicine, \\ Cairo University, Cairo, Egypt \\ 2Department of Medical Biochemistry and Molecular Biology, Faculty of Medicine, \\ Fayoum University, Faiyum, Egypt \\ ${ }^{3}$ Department of Rheumatology and Rehabilitation, Faculty of Medicine, Fayoum \\ University, Faiyum, Egypt \\ ${ }^{4}$ Department of Medical Physiology, Faculty of Medicine, Zagazig University, Zagazig, \\ Egypt \\ ${ }^{5}$ Department of Internal Medicine, Faculty of Medicine, Fayoum University, Faiyum, \\ Egypt \\ ${ }^{6}$ Department of Medical Microbiology and Immunology, Faculty of Medicine, Fayoum \\ University, Faiyum, Egypt \\ ${ }^{7}$ Department of Clinical Pathology, Faculty of Medicine, Fayoum University, Faiyum, \\ Egypt
}

Submitted: 9 October 2018; Accepted: 5 March 2019

Online publication: 19 March 2021

Arch Med Sci 2022; 18 (6): 1467-1474

DOI: https://doi.org/10.5114/aoms/105349

Copyright $\odot 2021$ Termedia \& Banach

\section{Abstract}

Introduction: The current study was designed to analyze whether polymorphisms of miR-146a and miR-155 are related to Behçet's disease (BD) in the Egyptian population.

Material and methods: A total of 96 unrelated BD patients and 100 healthy subjects were genotyped for miR-146a (rs2910164) and miR155 (rs767649) using real-time polymerase chain reaction.

Results: The results showed significant elevation in the frequency of rs2910164 GG and CC genotypes in BD patients compared with controls (adjusted $\mathrm{OR}=22.156,95 \% \mathrm{Cl}: 4.728-103.818 ; p<0.001$ and adjusted $\mathrm{OR}=40.358,95 \% \mathrm{Cl}: 8.928-182.440 ; p<0.001$, respectively). Also, the rs2910164 G allele conferred a higher risk of developing BD (adjusted $\mathrm{OR}=3.665,95 \% \mathrm{Cl}: 2.013-6.671 ; p<0.001)$. MiR-146a (rs2910164) polymorphism was a risk factor for susceptibility to BD in dominant, recessive and additive models of inheritance (all $p<0.001$ ), while the miR155 (rs767649) polymorphism was a risk factor in the recessive model only ( $p=0.021)$. GG and CG genotypes of rs2910164 were associated with higher Behcet's disease current activity index (BDCAI) and ocular involvement compared with CC genotype ( $p=0.005$ and $p=0.004$, respectively). Genotype AT of rs767649 was related to higher BDCAI $(p=0.026)$ compared with TT and AA genotypes.

Conclusions: miR-146a (rs2910164) and miR-155 (rs767649) are likely to play an important role in the Egyptian population in development of $\mathrm{BD}$ and also influence disease severity.

Key words: Behçet's disease, polymorphism, miR-146a, miR-155.

\author{
Corresponding author: \\ Omayma O. Abdelaleem \\ Department of Medical \\ Biochemistry and \\ Molecular Biology \\ Faculty of Medicine \\ Fayoum University \\ Faiyum, Egypt \\ Phone: 01094941030 \\ E-mail:dr.omayma@yahoo. \\ com
}


Olfat G. Shaker, Omayma O. Abdelaleem, Nermeen A. Fouad, Naglaa A. Ahmed, Hoda A. Hussein, Enas G. Ibrahem, Abdelrahmaan A. Mohamed, Othman M. Ahmed, Doaa Y. Ali

\section{Introduction}

Behçet's disease (BD) is a deteriorating inflammatory disease in which ulcers (genital and oral), ophthalmic inflammation and skin lesions exist [1]. It can also affect musculoskeletal, nervous, cardiovascular and gastrointestinal systems [2]. The pathogenesis of BD is vague; numerous studies have shown that $T$ cells and monocytes have an important role [3], as they are the predominant types of cells that infiltrate the tissues which are inflamed in BD patients $[4,5]$. In addition, disease activity correlates with increased peripheral $T$ cell populations with a pro-inflammatory shift $[6,7]$.

MicroRNAs (miRNAs) are 19-25 nucleotides in length (short non-coding RNAs). Their transcription suppresses expression of genes via binding target messenger RNA (mRNA), preventing translation and/or inducing degradation [8]. MiRNAs are the main controllers of genes as well as pathways of immune cells such as differentiation, proliferation and apoptosis [9]. Additionally, miRNA dysregulation is related to inflammation and autoimmunity $[10,11]$.

Many studies have revealed that miR-146a and miR-155 negatively regulated the innate immunity in autoimmune diseases [12, 13]. Moreover, miR$146 \mathrm{a}$ and miR-155 expression was documented to be dysregulated in $\operatorname{BD}[10,14]$.

Advances in genetic studies have established a significant relationship between genetic polymorphisms and disease susceptibility as well as response to treatment, allowing early diagnosis and treatment improvement in many diseases [15-19].

Delay in the diagnosis of $\mathrm{BD}$ is common as it depends on presence of numerous clinical manifestations. In addition, it is difficult to differentiate BD from other similar diseases. This delay may lead to the occurrence of serious complications such as cardiovascular and pulmonary with high mortality rates. Furthermore, early diagnosis allows use of effective treatment avoiding early permanent damage [20, 21].

Polymorphisms in miRNA, including miR-146a and miR-155, have received great attention in many studies, and they were observed to play a role in susceptibility to autoimmune diseases through affecting the expression of the miRNA targets [22, 23].

These findings suggested a vital role for epigenetic remodeling including miRNA dysregulation in the pathogenesis and the therapeutic response in BD.

The current study was performed to examine the association of miR-146a (rs2910164) and miR-155 (rs767649) polymorphisms with development of BD in the Egyptian population and to examine whether these polymorphisms correlate with the clinical data or the disease activity.

\section{Material and methods}

\section{Study participants}

Our case-control study recruited 96 patients (12 female, 84male) whose mean age was 33.81 \pm 7.86 years, from the Rheumatology and Rehabilitation Department, Faculty of Medicine, Fayoum University Hospital. The international criteria for BD were followed in the diagnosis [24]. A total of 100 healthy subjects (21 female, 79 male; mean age: $35.51 \pm 8.96$ years), matched for sex and age, and with negative family history of BD or any other inflammatory-autoimmune disease, were enrolled at the same time from the same geographical zone as control subjects. Each individual provided written consent before participation and after attaining authorization from the Research Ethics Committee in Fayoum, Faculty of Medicine. The study has been amended in accordance with the Helsinki Declaration guidelines.

Behcet's disease current activity index (BDCAI) was used to evaluate patients' disease activity status [25].

\section{DNA extraction and detection of genotyping}

Entire EDTA blood samples from all participants were used to extract genomic DNA, after being collected in vacuum blood tubes and preserved at $-20^{\circ} \mathrm{C}$, utilizing the QIA-magnification extraction kit (Qiagen, Valencia, CA) as stated by the manufacturer's guidelines. DNA samples were quantified using a NanoDrop (ND)-1000 spectrophotometer (Nano Drop Technologies, Inc. Wilmington, USA). Genotyping was achieved by means of RT PCR through the TaqMan allelic discrimination assay (Applied Biosystems, USA) using predesigned primer/probe sets on behalf of miRNA-146a rs2910164 (C/G) [c_15946974_10] and miR-155 rs767649 $(\mathrm{A} / \mathrm{T})[\mathrm{C}$ 2212229_10]. Probes were manufactured through reporter dye FAM or VIC covalently connected to the $5^{\prime}$ end, whereas quencher dye MGB connected to the $3^{\prime}$ end of the probe (Applied Biosystems, USA). Time of denaturation was $10 \mathrm{~min}$ at $95^{\circ} \mathrm{C}$ followed by 45 cycles at $92^{\circ} \mathrm{C}$ for $15 \mathrm{~s}$ then $60^{\circ} \mathrm{C}$ for $90 \mathrm{~s}$ for annealing and extension. Fluorescence was measured on completion of every cycle and at the endpoint. The Rotor-Gene Q Real Time PCR System (Qiagen, Valencia, CA, and USA) was used to check PCR products.

\section{Statistical analysis}

Statistical analyses were performed using SPSS version 25. Distribution of genotypes and frequencies of alleles of BD cases and controls were compared by means of the $\chi^{2}$ test. Analysis of variance (ANOVA) with the multiple comparisons post hoc test or unpaired $t$ test was used for 
comparisons between groups. The non-parametric Mann-Whitney $U$ test and Kruskal-Wallis test were applied for quantitative variables that are not normally distributed. Logistic regression was done to determine the odds ratio (OR) with 95\% confidence intervals and adjust for age and sex as possible confounders. The standard for significance was established at $p<0.05$ for all the tests. For analysis of Hardy-Weinberg equilibrium (HWE) the $\chi^{2}$ test was used $[26,27]$.

\section{Results}

\section{Demographic and clinical features of the study groups}

The current work included 96 patients with BD (12 female, 84 male) whose mean age was 33.81 \pm 7.86 years, and 100 healthy control individuals (21 female, 79 male) with an average age of 35.51 \pm 8.96 years.

The detailed demographic as well as clinical features of the combined patients with BD and healthy subjects are displayed in Table I. Age and gender were matched appropriately.

MiR-146a (rs2910164) and miR-155 (rs767649) genotypes were not in accordance with HWE $(p>0.05)$ in $\mathrm{BD}$ patients. However, in the healthy group rs2910164 genotypes (not rs767649) were in accordance with HWE $(p<0.05)$.

\section{Frequency distribution concerning the genotypes and alleles of miR-146a (rs2910164) and miR-155 (rs767649) in patients with BD and healthy controls}

In comparison to the healthy individuals, there was a significant difference in the frequency of miR-146a (rs2910164) genotypes in BD cases $(p<0.001)$. The frequencies of GG, CG, and CC genotypes were $29.2 \%, 66.7 \%$, and $4.2 \%$, respectively, in BD patients and were $10 \%, 40 \%$, and $50 \%$, respectively, in control individuals. Considering rs2910164 CC genotype a reference group, the frequencies of the GG and CG genotypes were significantly higher in $\mathrm{BD}$ patients than control group ( $p<0.001$ each), and these genotypes remained related to $\mathrm{BD}$ after adjustment for age, and sex (adjusted $\mathrm{OR}=22.16,95 \% \mathrm{Cl}: 4.73-103.82 ; p=$ 0.0001 ) and adjusted $\mathrm{OR}=40.36,95 \% \mathrm{Cl}: 8.93-$ 182.44; $p=0.0002$, respectively) (Table II).

When considering the dominant, recessive as well as additive models of inheritance, comparison of the miR-146a rs2910164 SNP among BD patients in relation to controls revealed an association with increased risk for BD (all $p=0.0001$ ) (Table II).

Also, the $G$ allele of miR-146a (rs2910164) was markedly higher in $\mathrm{BD}$ cases than in normal individuals (adjusted OR = 3.67, 95\% Cl: 2.01-6.67; $p=0.00003)$.
Table I. Characteristics of BD cases and controls

\begin{tabular}{|c|c|c|c|}
\hline Variables & $\begin{array}{l}\text { BD patients } \\
\quad(n=96)\end{array}$ & $\begin{array}{l}\text { Control group } \\
\quad(n=100)\end{array}$ & $P$-value \\
\hline Age [years] & $33.81 \pm 7.86$ & $35.51 \pm 8.96$ & 0.161 \\
\hline Sex, $n(\%):$ & & & 0.112 \\
\hline Females & $12(12.5)$ & $21(21)$ & \\
\hline Males & $84(87.5)$ & 79 (79) & \\
\hline BDCAI & $2(1-3)$ & & \\
\hline Oral ulcer & $36(37.5 \%)$ & & \\
\hline Genital ulcer & $12(12.5 \%)$ & & \\
\hline Skin lesions & $28(29.2 \%)$ & & \\
\hline $\begin{array}{l}\text { Positive } \\
\text { pathergy test }\end{array}$ & $44(45.8 \%)$ & & \\
\hline Arthritis & $4(4.2 \%)$ & & \\
\hline $\begin{array}{l}\text { Ocular } \\
\text { involvement }\end{array}$ & $32(33.3 \%)$ & & \\
\hline $\begin{array}{l}\text { Vascular } \\
\text { involvement }\end{array}$ & $12(12.5 \%)$ & & \\
\hline $\begin{array}{l}\text { Neurological } \\
\text { involvement }\end{array}$ & $4(4.2)$ & & \\
\hline
\end{tabular}
index.

Regarding miR-155 (rs767649), after using the AA genotype as a reference set, the TT and AT genotypes were not significant risk factors for $\mathrm{BD}$ (adjusted $\mathrm{OR}=1.24,95 \% \mathrm{Cl}: 0.28-5.42, p=0.776$ ) and (adjusted $\mathrm{OR}=0.51,95 \% \mathrm{Cl}: 0.13-2.05$, $p=0.342$ ), respectively.

Moreover, miR-155(rs767649) polymorphism was not associated with BD under the dominant and additive models. However, in the recessive model, the TT genotype was significantly associated with $\mathrm{BD}$ and remained associated with $\mathrm{BD}$ after adjustment for age and sex (adjusted OR = 2.32, 95\% Cl: 1.14-4.73, $p=0.021$ ).

Also, no significant difference was detected regarding allele frequency of miR-155 ( $r$ 767649) between BD cases and healthy subjects $(p=0.227)$.

\section{Results of haplotype analysis}

We examined the haplotype effect of rs2910164 and rs767649 polymorphisms in patients with BD relative to the control group ( $\mathrm{Ta}$ ble III). The carriage of combinations of rs2910164 $\mathrm{G}$ alleles + rs767649 A allele and rs2910164 G allele + rs767649 T allele were significantly associated with BD (adjusted OR $=6.9,95 \% \mathrm{Cl}$ : 3.0615.56, $p=0.0001$ and adjusted $\mathrm{OR}=3.38,95 \% \mathrm{Cl}$ : 2.01-5.7, $p=0.0001$, respectively).

As regards linkage disequilibrium between rs767649 and rs2910164, D' and $r^{2}$ values were 0.88 (95\% Cl: $0.64-0.96)$ and 0.286 , respectively for cases. For controls D' and $r^{2}$ values were 0.25 (95\% Cl: 0.03-0.55) and 0.024, respectively (Figure 1). 
Olfat G. Shaker, Omayma O. Abdelaleem, Nermeen A. Fouad, Naglaa A. Ahmed, Hoda A. Hussein, Enas G. Ibrahem, Abdelrahmaan A. Mohamed, Othman M. Ahmed, Doaa Y. Ali

Table II. Genotype and allele frequencies of miR-146a (rs2910164) and miR-155 (rs767649) polymorphisms in BD and healthy controls

\begin{tabular}{|c|c|c|c|c|c|c|c|}
\hline $\begin{array}{l}\text { Genotype } \\
\text { and allele }\end{array}$ & & $\begin{array}{c}\text { BD } \\
n(\%)\end{array}$ & $\begin{array}{c}\text { Controls } \\
n(\%)\end{array}$ & $\begin{array}{l}\text { Unadjusted } \\
\text { OR }(95 \% \mathrm{Cl})\end{array}$ & $P$-value & $\begin{array}{c}\text { Adjusted } \\
\text { OR }(95 \% \mathrm{Cl})\end{array}$ & $P$-value \\
\hline \multirow{3}{*}{$\begin{array}{l}\text { miR-146a } \\
\text { rs2910164 }\end{array}$} & GG & $28(29.2)$ & $10(10)$ & $35(10.05-121.97)$ & $<0.001^{*}$ & $22.16(4.73-103.82)$ & $<0.001^{*}$ \\
\hline & CG & $64(66.7)$ & $40(40)$ & $20(6.71-59.63)$ & $<0.001^{*}$ & $40.358(8.93-182.44)$ & $<0.001^{*}$ \\
\hline & $\mathrm{CC}$ & $4(4.2)$ & $50(50)$ & 1 & & 1 & \\
\hline \multirow{2}{*}{$\begin{array}{l}\text { Dominant } \\
\text { model }\end{array}$} & $\mathrm{GG}+\mathrm{CG}$ & $92(95.8)$ & $50(50)$ & $23(7.85-67.39)$ & $<0.001^{\star}$ & $31.48(7.97-124.4$ & $<0.001^{*}$ \\
\hline & CC & $4(4.2)$ & $50(50)$ & 1 & & 1 & \\
\hline \multirow{2}{*}{$\begin{array}{l}\text { Recessive } \\
\text { model }\end{array}$} & GG & $28(29.2)$ & $10(10)$ & $3.71(1.69-8.15)$ & $<0.001^{\star}$ & $1.81(0.65-4.99)$ & 0.255 \\
\hline & $\mathrm{CC}+\mathrm{CG}$ & $68(70.8)$ & $90(90)$ & 1 & & 1 & \\
\hline \multirow{2}{*}{$\begin{array}{l}\text { Additive } \\
\text { model }\end{array}$} & GG & $28(87.5)$ & $10(16.7)$ & $35(10.05-121.97)$ & $<0.001^{*}$ & $24.46(5.61-106.73)$ & $<0.001^{*}$ \\
\hline & CC & $4(12.5)$ & $50(83.3)$ & 1 & & 1 & \\
\hline \multirow[t]{2}{*}{ Alleles } & $G$ & $120(62.5)$ & $60(30)$ & $3.89(2.55-5.92)$ & $<0.001^{*}$ & $3.67(2.01-6.67)$ & $<0.001^{*}$ \\
\hline & C & $72(37.5)$ & $140(70)$ & 1 & & 1 & \\
\hline \multirow{3}{*}{$\begin{array}{l}\text { miR-155 } \\
\text { rs767649 }\end{array}$} & TT & $28(29.2)$ & $15(15)$ & $1.867(0.47-7.49)$ & 0.379 & $1.24(0.28-5.42)$ & 0.776 \\
\hline & AT & $63(65.6)$ & $80(80)$ & $0.79(0.22-2.84)$ & 0.715 & $0.51(0.12-2.05)$ & 0.342 \\
\hline & AA & $5(5.2)$ & $5(5)$ & & 1 & & 1 \\
\hline \multirow{2}{*}{$\begin{array}{l}\text { Dominant } \\
\text { model }\end{array}$} & $\mathrm{TT}+\mathrm{AT}$ & $91(94.8)$ & $95(95)$ & $0.96(0.27-3.42)$ & 0.947 & $0.65(0.16-2.53)$ & 0.531 \\
\hline & $A A$ & $5(5.2)$ & $5(5)$ & & 1 & & 1 \\
\hline \multirow{2}{*}{$\begin{array}{l}\text { Recessive } \\
\text { model }\end{array}$} & TT & $28(29.2)$ & $15(15)$ & $2.33(1.16-4.72)$ & $0.018^{*}$ & $2.32(1.14-4.73)$ & $0.021^{*}$ \\
\hline & $A A+A T$ & $68(70.8)$ & $85(85)$ & 1 & & 1 & \\
\hline \multirow{2}{*}{$\begin{array}{l}\text { Additive } \\
\text { model }\end{array}$} & $\mathrm{TT}$ & $28(84.8)$ & $15(75)$ & $1.867(0.47-7.49)$ & 0.465 & $0.99(0.19-5.11)$ & 0.988 \\
\hline & AA & $5(15.2)$ & $5(25)$ & & 1 & & 1 \\
\hline \multirow[t]{2}{*}{ Alleles } & $\mathrm{T}$ & $119(62)$ & $110(55)$ & $1.334(0.89-2)$ & 0.161 & $1.29(0.86-1.93)$ & 0.227 \\
\hline & A & $73(38)$ & $90(45)$ & 1 & & 1 & \\
\hline
\end{tabular}

Data are expressed as $n$ (\%). BD - Behcet's disease, $O R$ - odds ratio, $C l$ - confidence interval. *Statistical significance $(p<0.05)$.

Table III. Haplotype analysis of miR-146a (rs2910164) and miR-155 (rs767649) polymorphisms in BD compared to healthy controls

\begin{tabular}{|c|c|c|c|c|c|c|}
\hline Haplotype & $\begin{array}{c}\text { BD } \\
n(\%)\end{array}$ & $\begin{array}{c}\text { Controls } \\
n(\%)\end{array}$ & $\begin{array}{l}\text { Unadjusted } \\
\text { OR }(95 \% \mathrm{Cl})\end{array}$ & $P$-value & $P$-value & $P$-value \\
\hline $\begin{array}{l}\text { rs2910164 C allele + } \\
\text { rs767649 A allele }\end{array}$ & $40(20.8)$ & $80(40)$ & 1 & & 1 & \\
\hline $\begin{array}{l}\text { rs2910164 G allele + } \\
\text { rs767649 A allele }\end{array}$ & $33(17.2)$ & $10(5)$ & $6.6(2.96-14.73)$ & $<0.001^{*}$ & $6.9(3.06-15.56)$ & $<0.001^{*}$ \\
\hline $\begin{array}{l}\text { rs2910164 C allele + } \\
\text { rs767649 T allele }\end{array}$ & $32(16.7)$ & $60(30)$ & $1.07(0.60-1.89)$ & 0.825 & $1.06(0.59-1.89)$ & 0.850 \\
\hline $\begin{array}{l}\text { rs2910164 G allele + } \\
\text { rs767649 T allele }\end{array}$ & $87(45.3)$ & $50(25)$ & $3.48(2.08-5.82)$ & $<0.001^{*}$ & $3.38(2.01-5.7)$ & $<0.001^{*}$ \\
\hline
\end{tabular}

Data are expressed as $n$ (\%). BD - Behcet's disease, $O R$ - odds ratio, $C l$ - confidence interval. *Statistical significance ( $p<0.05)$.

Relation between miRNA-146a (rs2910164) and miRNA-155 (rs767649) genotypes and the clinical data of $B D$ patients

Concerning rs2910164, a significant relationship was documented among patients carrying GG and CG genotypes and degree of BDCAI activity compared with patients carrying CC genotype $(p<0.05$, each) (Figure 2).

Interestingly, the percentage of $\mathrm{BD}$ patients with eye manifestations was considerably higher in patients with GG or CG genotypes relative to CC genotype as well as in patients carrying GG genotype compared with CG genotype $(p=0.004)$. Additionally, the percentage of BD patients who had neurological symptoms was significantly higher in patients carrying GG genotype than in patients with CG or CC genotype ( $p=0.018)$ (Table IV).

For rs767649, patients carrying AT genotype showed higher BDCAl activity $(p=0.026)$, compared with TT or AA carriers (Figure 3 ), while no significant association was found between the 


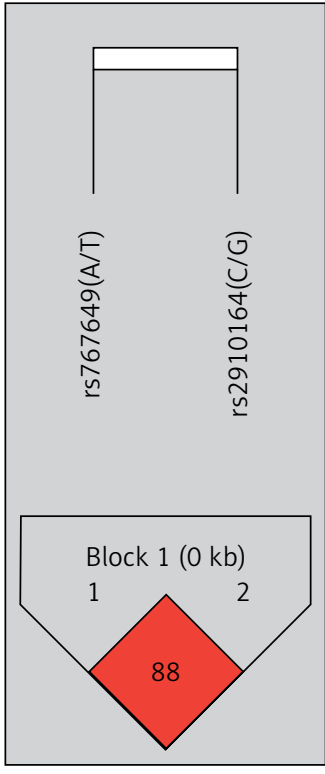

LD in case

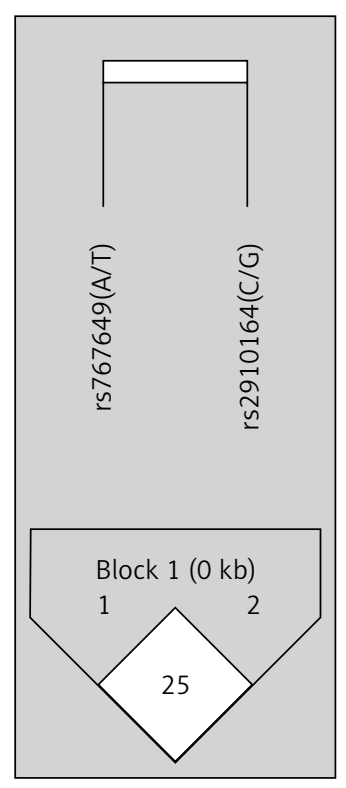

LD in controls
Figure 1. Linkage disequilibrium (LD) between rs767649 and rs2910164, $D^{\prime}$ and $r^{2}$ values were 0.88 (95\% Cl: $0.64-0.96)$ and 0.286 , respectively for cases. For controls, $D^{\prime}$ and $r^{2}$ values were 0.25 (95\% Cl: 0.03-0.55) and 0.024, respectively

rs767649 polymorphism and the other clinical data (all $p>0.05$ ) (Table IV).

\section{Discussion}

MiRNAs are evolving as essential regulators of inflammatory immune responses [28]. It has been proposed that genetic variants of miRNAs affect this regulatory role of miRNAs, thereby explaining

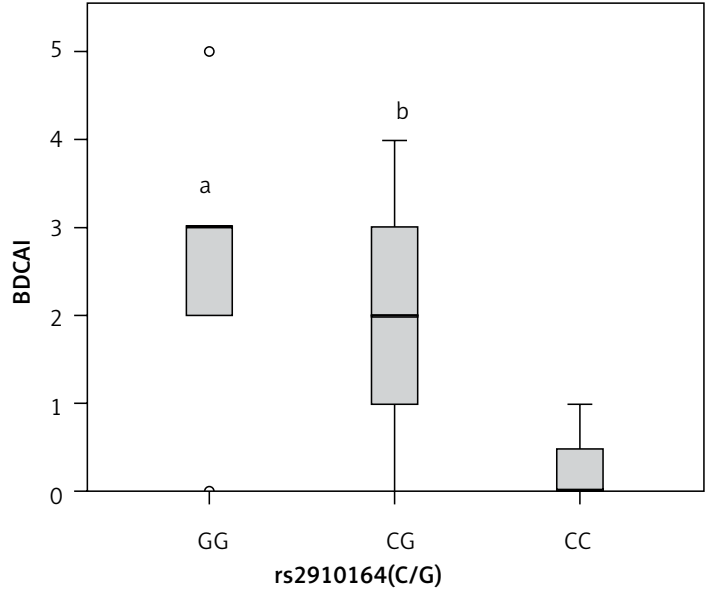

Figure 2. Box plot representation of Behcet disease current activity index (BDCAI) in different rs2910164 genotypes (GG, $n=28, \mathrm{CG}, n=64, \mathrm{CC}$, $n=4$ ). Data are expressed as median (interquartile range). ${ }^{a}$ Statistical significance $(p<0.05)$ compared with CC. ${ }^{\text {SS}}$ Statistical significance $(p<0.05)$ compared with CC

why a certain variant may contribute to autoimmune or inflammatory diseases [29].

The present study investigated the genotype effects of rs2910164 of miR-146a and rs767649 of miR-155 on BD predisposition and activity in the Egyptian population with BD.

In the present study, we found that the frequencies of the GG and CG genotypes were significantly higher in BD patients than in control subjects. Additionally, the $G$ allele frequency of miR-146a (rs2910164) was found to be significantly higher in $\mathrm{BD}$ patients than in normal control subjects.

Table IV. Effect of miR-146a (rs2910164) and miR-155 (rs767649) on clinical features in BD patients

\begin{tabular}{|c|c|c|c|c|c|c|c|c|c|}
\hline \multirow[t]{2}{*}{ Variable } & & \multicolumn{4}{|c|}{ miR-146a (rs2910164) } & \multicolumn{4}{|c|}{ miR-155(rs767649) } \\
\hline & & GG & CG & $\mathrm{CC}$ & $P$-value & TT & AT & AA & $P$-value \\
\hline \multirow[t]{2}{*}{ Oral ulcer } & Present & $8(28.6)$ & $28(43.8)$ & $0(0)$ & 0.127 & $8(28.6)$ & $27(42.9)$ & $1(20)$ & 0.353 \\
\hline & Absent & $20(71.4)$ & $36(56.2)$ & $4(100)$ & & $20(71.4)$ & $36(57.1)$ & $4(80)$ & \\
\hline \multirow[t]{2}{*}{ Genital ulcer } & Present & $4(14.3)$ & $8(12.5)$ & $0(0)$ & 1 & $4(14.3)$ & $8(12.7)$ & $0(0)$ & 1 \\
\hline & Absent & $24(85.7)$ & $56(87.5)$ & $4(100)$ & & $24(85.7)$ & $55(87.3)$ & $5(100)$ & \\
\hline \multirow[t]{2}{*}{ Skin lesions } & Present & $8(28.6)$ & $20(31.2)$ & $0(0)$ & 0.570 & $4(14.3)$ & $22(34.9)$ & $2(40)$ & 0.087 \\
\hline & Absent & $20(71.4)$ & $44(68.8)$ & $4(100)$ & & $24(85.7)$ & $41(65.1)$ & $3(60)$ & \\
\hline \multirow[t]{2}{*}{ Arthritis } & Present & $0(0)$ & $4(6.2)$ & $0(0)$ & 0.419 & $4(14.3)$ & $0(0)$ & $0(0)$ & $0.024^{\mathrm{ab}}$ \\
\hline & Absent & $28(100)$ & $60(93.8)$ & $4(100)$ & & $24(85.7)$ & $63(100)$ & $5(100)$ & \\
\hline \multirow{2}{*}{$\begin{array}{l}\text { Ocular } \\
\text { involvement }\end{array}$} & Present & $16(57.1)$ & $16(25)$ & $0(0)$ & $0.004^{\mathrm{abc}}$ & $8(28.6)$ & $22(34.9)$ & $2(40)$ & 0.754 \\
\hline & Absent & $12(42.9$ & $48(75)$ & $4(100)$ & & $20(71.4)$ & $41(65.1)$ & $3(60)$ & \\
\hline \multirow{2}{*}{$\begin{array}{l}\text { Vascular } \\
\text { involvement }\end{array}$} & Present & $4(14.3)$ & $8(12.5)$ & $0(0)$ & 1 & $4(14.3)$ & $8(12.7)$ & $0(0)$ & 1 \\
\hline & Absent & $24(85.7)$ & $56(87.5)$ & $4(100)$ & & $24(85.7)$ & $55(87.3)$ & $5(100)$ & \\
\hline \multirow{2}{*}{$\begin{array}{l}\text { Neurological } \\
\text { involvement }\end{array}$} & Present & $4(14.3)$ & $0(0)$ & $0(0)$ & $0.018^{a b}$ & $0(0)$ & $3(4.8)$ & $1(20)$ & 0.119 \\
\hline & Absent & $24(85.7)$ & $64(100)$ & $4(100)$ & & $28(100)$ & $60(95.2)$ & $4(80)$ & \\
\hline
\end{tabular}

a Significant difference between GG versus CG or TT versus AT. bSignificant difference between GG versus CC or TT versus AA. 'Significant difference between $C G$ versus $C C$. 


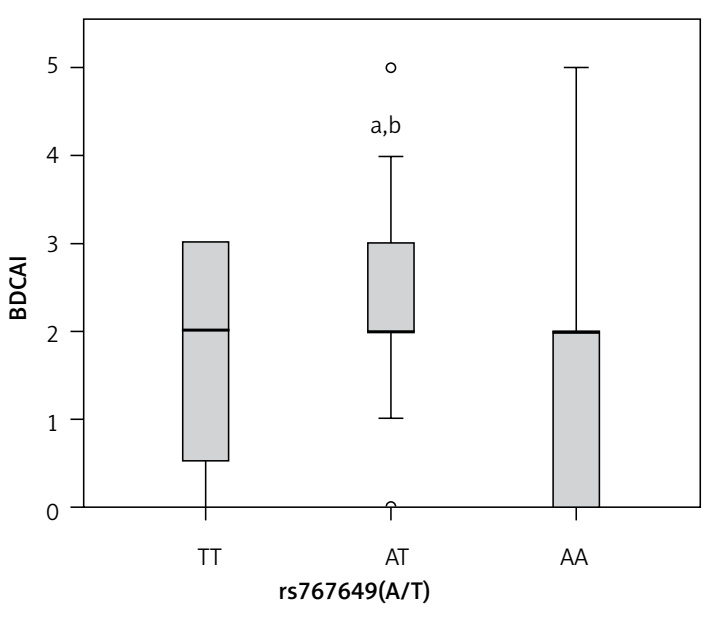

Figure 3. Behcet disease current activity index (BDCAI) in different rs767649 genotypes (TT, $n=28$, AT, $n=63, \mathrm{AA}, n=5)$. Data are expressed as median (interquartile range). aStatistical significance $(p<0.05)$ compared with TT. ${ }^{b}$ Statistical significance $(p<0.05)$ compared with AA

Consistent with the aforementioned results, in a previous study conducted on the Chinese population, the frequency of the CG genotype was also found to be significantly higher in BD patients when compared with controls. Also they revealed lower frequency of CC genotype as well as the $C$ allele in BD patients than in healthy control subjects. Moreover, they reported higher levels of miR-146a in cases with GG genotype than in cases with CC and GC genotypes. Furthermore, they found significantly reduced levels of miR-146a , IL-7, TNF- $\alpha$, as well as IL- $1 \beta$ in patients carrying CC than those with GG [14].

Another very recent study in Egypt which enrolled smaller numbers of patients and controls revealed elevation of the incidence of GG genotype, which was not significantly different in the $\mathrm{BD}$ patients relative to the controls [30].

Functional studies showed that miRNA-146a is included in certain immune-mediated diseases by regulating multiple pathways involving innate and adaptive immune systems [13]. Attenuation of interleukin (IL)-1 receptor-associated kinase 1 (IRAK1), NF-KB and tumor necrosis factor (TNF) receptor-associated factor 6 (TRAF6) is one of the essential actions of miR-146a [31]. MiR-146a is broadly confirmed to be related to immune diseases including BD [32]. Additionally, the expression level of miR-146 was verified to be significantly upregulated in patients with $\mathrm{BD}$ relative to control individuals. It was found that miR-146a expression was related to vascular and ocular manifestations [30].

Furthermore, miR-146a (rs2910164) polymorphism has been previously identified as a risk factor in developing SLE and RA by modulating its expression, affecting the amount of miR-146a, which may subsequently lead to disease development $[33,34]$.

For rs767649 polymorphism, no significant difference was found in the present study between BD patients and normal control subjects except under the recessive model, where the TT genotype was markedly linked to BD and remained associated with it after adjustment for age and sex.

MiR-155 is one of the early miRNAs that was revealed to be included in the pathogenesis of autoimmune diseases such as RA and SLE [35, 36]. Moreover, this miRNA was reported to be overexpressed in CD4+ $T$ cells in BD patients during disease activity through regulating the Th17 immune response via targeting E26 transformation-specific-1 (Ets-1) [37]. Additionally, Kolahi et al. reported significantly higher levels of miR-155 in patients with BD [38]. They revealed that miR-155 was positively correlated with the levels of TNF- $\alpha$ and negatively associated with CTLA-4.

However, Zhou et al. observed reduced levels of miR-155 in BD patients with active uveitis. They reported that miR-155 constrains the secretion of IL-6 and IL-1b and increases the secretion of IL-10 [10].

Emerging evidence suggests that the rs767649 SNP situated in the upstream region of premiR-155 disturbs the binding of regulatory factors including NF- $\mathrm{KB}$ to miR-155, and this polymorphism affects the expression of miR-155 [39]. To the best of our knowledge, the association of miR-155 (rs767649) with BD is first studied in this work.

In a study by Ji et al., TT genotype of rs767649 was found to be associated with higher risk and poor survival of patients with hepatocellular carcinoma; they also stated that the T allele contributed to upregulation of miR-155 [39].

Similarly, Xie et al. proposed that TT genotype of the above-mentioned SNP was linked to increased risk of non-small cell lung cancer. They suggested that TT genotype increases miR-155 expression, which contributes to the increased risk of lung cancer [40].

However, Assmann et al. demonstrated that miR-155(rs767649) was related to protection from type 1 diabetes mellitus [41].

In the current study, the rs2910164 GG and CG genotypes were associated with higher disease activity in BD patients, depending on the BDCAI score. Similarly, the same genotypes (GG and CG) were associated with more frequent ocular involvement compared with CC genotype. Moreover, ocular involvement was significantly increased in BD patients carrying GG genotype when compared to CG genotype. Additionally, presence of neurological manifestations was significantly associated with the GG genotype more than CG or CC genotypes. 
Previous studies have demonstrated that rs2910164 was associated with high miR-146a expression in numerous autoimmune and inflammatory disorders including BD [14, 34]. It has been shown that this SNP may influence the production of proinflammatory cytokines such as TNF- $\alpha$, IL-17, and IL-1 $\beta$, being more highly secreted in $\mathrm{BD}$ patients carrying GG genotype than those with CC genotype.

Moreover, it was reported that IL-17 was increased in BD patients and was significantly associated with ocular involvement, disease activity and neurological manifestations [42, 43].

The results of the current study are in agreement with a previous study which concluded that the GG genotype and G allele were markedly associated with pediatric uveitis in Han Chinese [44]. Furthermore, miR-146a level was significantly higher in autoimmune uveoretinitis [45].

Regarding miR-155 (rs767649), the current study further confirmed that patients carrying AT genotype presented with higher BDCAI scores compared with TT or AA carriers. However, there are no reports on the association of the aforementioned SNP with BD.

The following limitations should be considered: First, the present study is a single case-control study with a relatively small sample size, so further studies with large samples in other ethnic groups are required. Second, the possible mechanisms of how these gene polymorphisms affect $\mathrm{BD}$ should be evaluated. Finally, the present study cannot rule out that other SNPs located in miR146a and miR-155 may be associated with BD.

In conclusion, the present study suggested that the miR-146a (rs2910164) and miR-155 (rs767649) polymorphisms are associated with increased risk of BD and can affect disease activity and severity in the Egyptian population.

\section{Conflict of interest}

The authors declare no conflict of interest.

\section{References}

1. Pineton de Chambrun M, Wechsler B, Geri G, Cacoub P, Saadoun D. New insights into the pathogenesis of Behcet's disease. Autoimmun Rev 2012; 11: 687-98.

2. Mat MC, Sevim A, Fresko I, Tüzün Y. Behcet's disease as a systemic disease. Clin Dermatol 2014; 32: 435-42.

3. Tulunay A, Dozmorov MG, Ture-Ozdemir F, et al. Activation of the JAK/STAT pathway in Behcet's disease. Genes Immun 2015; 16: 170-5.

4. Hirohata S. Histopathology of central nervous system lesions in Behcet's disease. J Neurol Sci 2008; 267: 41-7.

5. Hughes T, Ture-Ozdemir F, Alibaz-Oner F, Coit P, Direskeneli $\mathrm{H}$, Sawalha AH. Epigenome-wide scan identifies a treatment responsive pattern of altered DNA methylation among cytoskeletal remodeling genes in monocytes and CD4+ T cells from patients with Behcet's disease. Arthritis Rheumatol 2014; 66: 1648-58.
6. Direskeneli H, Fujita H, Akdis CA. Regulation of Th17and regulatory $\mathrm{T}$ cells in patients with Behcet disease. J Allergy Clin Immunol 2011; 128: 665-6.

7. Geri G, Terrier B, Rosenzwajg M, Saadoun D. Critical role of IL-21 in modulating Th17 and regulatory T cells in Behcet disease. J Allergy Clin Immunol 2011; 128: 655-64.

8. Liu, Y, Li H, Xiao T, Lu Q. Epigenetics in immune-mediated pulmonary diseases. Clin Rev Allergy Immunol 2013; 45: 314-30.

9. Bartel DP. MicroRNAs: genomics, biogenesis, mechanism, and function. Cell 2004; 116: 281-97.

10. Zhou Q, Xiao X, Wang C, et al. Decreased microRNA-155 expression in ocular Behcet's disease but not in Vogt Koyanagi Harada syndrome. Invest Ophthalmol Vis Sci 2012; 53: 5665-74.

11. Zeng, L, Cui J, Wu H, Lu Q. The emerging role of circulating microRNAs as biomarkers in autoimmune diseases. Autoimmunity 2014; 47: 419-29.

12. Faraoni, I, Antonetti FR, Cardone J, Bonmassar E. miR155 gene: a typical multifunctional microRNA. Biochim Biophys Acta 2009; 1792: 497-505.

13. Tang $\mathrm{Y}$, Luo $\mathrm{X}$, Cui $\mathrm{H}$, et al. MicroRNA-146A contributes to abnormal activation of the type I interferon pathway in human lupus by targeting the key signaling proteins. Arthritis Rheum 2009; 60: 1065-75.

14. Zhou Q, Hou S, Liang L, Li X, Tan X, Wei L. MicroRNA-146a and Ets-1 gene polymorphisms in ocular Behcet's disease and Vogt-Koyanagi-Harada syndrome. Ann Rheum Dis 2014; 73: 170-6.

15. Zhai C, Li S, Feng W, et al. Association of interleukin-17a rs2275913 gene polymorphism and asthma risk: a meta-analysis. Arch Med Sci 2018; 14: 1204-11.

16. Belohlavkova P, Vrbacky F, Voglova J, et al. The significance of enzyme and transporter polymorphisms for imatinib plasma levels and achieving an optimal response in chronic myeloid leukemia patients. Arch Med Sci 2018; 14: 1416-23.

17. Totomoch-Serra A, Muñoz ML, Burgueño J, Revilla-Monsalve MC, Diaz-Badillo A. Association of common polymorphisms in the VEGFA and SIRT1 genes with type 2 diabetes-related traits in Mexicans. Arch Med Sci 2018; 14: 1361-73.

18. Elshamaa MF, Hamza H, Abd El Rahman N, et al. Association of ficolin-2 (FCN2) functional polymorphisms and protein levels with rheumatic fever and rheumatic heart disease: relationship with cardiac function. Arch Med Sci Atheroscler Dis 2018; 3: e142-55.

19. Sinaga BYM, Amir Z, Siagian P. The role of Fokl polymorphism of vitamin $D$ receptor gene and vitamin $D$ level in multidrug-resistant tuberculosis occurrence in Medan city, Indonesia. Arch Med Sci Civil Dis 2018; 3: e153-7.

20. Chae EJ, Do KH, Seo JB, et al. Radiologic and clinical findings of Behçet disease: comprehensive review of multisystemic involvement. Radiographics 2008; 28: e31.

21. Calamia KT, Kaklamanis PG. Behçet's disease: recent advances in early diagnosis and effective treatment. Curr Rheumatol Rep 2009; 10: 349-55.

22. Apparailly F. Looking for microRNA polymorphisms as new rheumatoid arthritis risk loci? Joint Bone Spine 2010; 77: 377-9.

23. Zhao ZZ, Croft L, Nyholt DR, et al. Evaluation of polymorphisms in predicted target sites for micro RNAs differentially expressed in endometriosis. Mol Hum Reprod 2011; 17: 92-103.

24. Davatchi F, Assaad-Khalil S, Calamia KT, et al. The International Criteria for Behçet's Disease (ICBD): a collaborative study of 27 countries on the sensitivity and spec- 
ificity of the new criteria. J Eur Acad Dermatol Venereo 2014; 28: 338-47.

25. Bhakta BB, Brennan P, James TE, et al. Behçet's disease: evaluation of a new instrument to measure clinical activity. Rheumatology 1999; 38: 728-33.

26. AbdulAzeez S, Al-Nafie AN, Al-Shehri A, et al. Intronic polymorphisms in the CDKN2B-AS1 gene are strongly associated with the risk of myocardial infarction and coronary artery disease in the Saudi Population. Int J Mol Sci 2016; 17: 395.

27. Alyousef YM, Borgio JF, AbdulAzeez S, et al. Association of MBL2 Gene polymorphism with dental caries in Saudi children. Caries Res 2017; 51: 12-6.

28. Bushati N, Cohen SM. microRNA functions. Annu Rev Cell Dev Biol 2007; 23: 175-205.

29. Cammaerts S, Strazisar M, De Rijk P, Del Favero J. Genetic variants in microRNA genes: impact on microRNA expression, function, and disease. Front Genet 2015; 6: 186.

30. Ibrahim W, Sakr BR, Obaya E, Ghonem H. MicroRNA146a expression and microRNA-146a rs2910164 polymorphism in Behcet's disease patients. Clin Rheumatol 2019; 38: 397-402.

31. Boldin MP, Baltimore D. MicroRNAs, new effectors and regulators of NF-кB. Immunol Rev 2012; 246: 205-20.

32. Puccetti A, Pelosi A, Fiore PF, Patuzzo G, Lunardi C, Dolcino M. MicroRNA expression profiling in Behçet's disease. J Immunol Res 2018; 2018: 2405150.

33. Luo $\mathrm{X}$, Yang $\mathrm{W}$, Ye $\mathrm{DQ}$, et al. A functional variant in $\mathrm{mi}-$ croRNA-146a promoter modulates its expression and confers disease risk for systemic lupus erythematosus. PLoS Genetics 2011; 7: e1002128.

34. Ayeldeen, G, Nassar Y, Ahmed H, Shaker O, Gheita T. Possible use of miRNAs-146a and -499 expression and their polymorphisms as diagnostic markers for rheumatoid arthritis. Mol Cell Biochem 2018; 449: 145-56.

35. Wang G, Tam LS, Li EK, et al. Serum and urinary cell-free MiR-146a and MiR-155 in patients with systemic lupus erythematosus. J Rheumatol 2010; 37: 2516-22.

36. Kurowska-Stolarska M, Alivernini S, Ballantine LE, et al. MicroRNA-155 as a proinflammatory regulator in clinical and experimental arthritis. Proc Natl Acad Sci USA 2011; 108: 11193-8.

37. Na SY, Park MJ, Park S, Lee E. MicroRNA-155 regulates the Th17 immune response by targeting Ets- 1 in Behçet's disease. Clin Exp Rheumatol 2016; 6: S56-63.

38. Kolahi S, Farajzadeh MJ, Alipour S, et al. Determination of mir-155 and mir-146a expression rates and its association with expression level of TNF- $\alpha$ and CTLA4 genes in patients with Behcet's disease. Immunol Lett 2018; 204: 55-9.

39. Ji J, Xu M, Tu J, et al. MiR-155 and its functional variant rs767649 contribute to the susceptibility and survival of hepatocellular carcinoma. Oncotarget 2016; 7: 60303-9.

40. Xie $\mathrm{K}, \mathrm{Ma} \mathrm{H}$, Liang $\mathrm{C}$, et al. A functional variant in miR155 regulation region contributes to lung cancer risk and survival. Oncotarget 2015; 6: 42781-92.

41. Assmann TS, Duarte GC, Brondani LA, et al. Polymorphisms in genes encoding miR-155 and miR-146a are associated with protection to type 1 diabetes mellitus. Acta Diabetol 2017; 54: 433-41.

42. Geri G, Terrier B, Rosenzwajg M, Saadoun D. Critical role of IL-21 in modulating TH17 and regulatory T cells in Behcet disease. J Allergy Clin Immunol 2011; 128: 655-64.

43. Al-Zifzaf DS, Abir N, Mokbe AN, Abdelaziz D. Interleukin-17 in Behçet's disease: relation with clinical picture and disease activity. Egypt Rheum Rehabil 2015; 42: 34-8.
44. Wei L, Zhou O, Hou S, et al. MicroRNA-146a and Ets-1 gene polymorphisms are associated with pediatric uveitis. PLoS One 2014; 9: e91199.

45. Watanabe T, Keino H, Kudo A, Sato Y, Okada AA. MicroRNAs in retina during development of experimental autoimmune uveoretinitis in rats. $\mathrm{Br} J$ Ophthalmol 2016; 100: 425-31. 